\title{
APLIKASI KAMUS BAHASA TALIABU BERBASIS ANDROID DENGAN MENGGUNAKAN METODE BINARY SEARCH
}

\author{
Bayu Sulistio $^{1}$, Salkin Lutfi ${ }^{2}$, Ridwan $^{3}$ \\ Program Studi Teknik Informatika, Fakultas Teknik, Universitas Khairun \\ Jl. Jati Metro, Kota Ternate Selatan \\ E-Mail : Bayusulistio07@gmail.com ${ }^{1}, \underline{\text { Salkin.lutfi@gmail.com }}{ }^{2}, \underline{\text { Ridho8983@yahoo.co.id }}$
}

(Naskah masuk: 20 April 2019, diterima untuk diterbitkan: 20 Oktober 2019)

\begin{abstract}
Abstrak
Bahasa merupakan alat komunikasi manusia yang digunakan untuk mengadakan hubungan dalam pergaulan seharihari, selain itu juga berfungsi sebagai sarana untuk menyampaikan informasi. Bahasa daerah meruapakan bahasa khas yang berasal dari salah satu daerah di suatu negara atau wilayah. Namun penggunaan bahasa daerah telah mengalami penurunan penggunaan dalam bahasa komunikasi keseharian, bahasa Taliabu merupakan salah satu bahasa yang hampir punah karena mulai jarang di gunakan dalam kehidupan masyarakat. Melestarikan bahasa Taliabu sangat penting dilakukan agar bahasa Taliabu tidak punah, media penerjemah atau kamus dapat menjadi solusi untuk membantu masyarakat untuk mempelajari bahasa Taliabu. Tujuan dari penelitian ini adalah untuk menghasilkan rancangan aplikasi kamus bahasa Taliabu berbasis android menggunakan metode binary search. Aplikasi ini di buat dengan menggunakan Bahasa pemrograman PHP dan java dengan prototype sebagai pengembangan sistemnya. Aplikasi ini dapat berjalan di web maupun di android dengan metode binary search sebagai metode pencarian katanya. Dengan adanya binary search proses pencarian dapat di lakukan dengan cepat karena binary search sendiri memiliki prinsip pencarian membagi dua, sehingga proses pencarian lebih cepat.
\end{abstract}

Kata Kunci : Kamus, Android, Prototype, binary search

\section{ANDROID BASED DICTIONARY TALIABU LANGUAGE USING BINARY SEARCH METHOD}

\begin{abstract}
Language is a human communication tool that is used to establish relationships in everyday life, besides that it also functions as a means to convey information. Regional languages are typical languages originating from one region in a country or region. However, the use of regional languages has experienced a decline in the use of everyday communication languages, Taliabu language is one of the languages that is almost extinct because it is rarely used in people's lives. Preserving Taliabu language is very important so that Taliabu language is not extinct, translator media or dictionaries can be a solution to help people learn Taliabu language. The purpose of this study is to produce a design of an Android based Taliabu language dictionary application using the binary search method. This application is created using the PHP and java programming language with the prototype as the system development. This application can run on the web or on android with the binary serach method as a search method he said. With the binary serach the search process can be done quickly because the binary serach itself has the principle of searching to divide in two, so the search process is faster.
\end{abstract}

Keywords: Dictionary, Android, Prototype, binary search

\section{PENDAHULUAN}

Bahasa merupakan alat komunikasi manusia yang digunakan untuk mengadakan hubungan dalam pergaulan sehari-hari, selain itu juga berfungsi sebagai sarana untuk menyampaikan informasi [1]. Di Indonesia terdapat 700 ragam bahasa daerah yang di gunakan [2].
Bahasa daerah meruapakan bahasa khas yang berasal dari salah satu daerah di suatu negara atau wilayah.

Namun penggunaan bahasa daerah telah mengalami penurunan penggunaan dalam bahasa komunikasi keseharian[3]. Bahasa Taliabu merupakan salah satu bahasa yang hampir punah karena mulai jarang di gunakan dalam kehidupan masyarakat [4]. Ada beberapa sebab bahasa Taliabu mulai jarang digunakan 
dikehidupan seharai-hari di dalam masyarakat salah satunya adalah anak-anak atau remaja kurang begitu memahami atau mengerti tentang bahasa daerahnya sendiri. Anak muda sekarang ini juga lebih suka berkomunikasi dengan bahasa gaul dari pada bahasa daerah yang mereka gunakan. Melestarikan bahasa Taliabu sangat penting dilakukan agar bahasa Taliabu tidak punah. Media penerjemah atau kamus dapat menjadi solusi untuk membantu masyarakat untuk mempelajari bahasa Taliabu [3].

Perkembangan teknologi informasi sangat pesat salah satunya adalah smartphone dengan sistem operasi android. Android merupakan sebuah sistem operasi untuk perangkat mobile berbasis linux yang mencakup sistem operasi, middleware dan aplikasi. Android merupakan platform mobile pertama yang lengkap, terbuka, dan bebas, baik itu sistem operasinya, aplikasi dan tool pengembangan [1]. Karena hal tersebut smartphone dengan sistem operasi android banyak digunakan oleh masyarakat khusunya anak-anak maupun remaja sekarang ini.

Berdasarkan masalah di atas penulis mengusulkan judul "Aplikasi kamus bahasa Taliabu berbasis android menggunakan metode Binary Search" agar dapat membantu masyarakat dalam mempelajari bahasaTaliabu.

\section{TINJAUAN PUSTAKA}

\section{A. Bahasa Taliabu}

Bahasa Taliabu adalah salah satu bahasa yang terdapat di Maluku Utara. Sementara itu, di wilayah Maluku terdapat lebih dari 80 bahasa daerah, 22 bahasa terancam punah dan 11 bahasa punah. Di Maluku Utara terdapat 30 bahasa, yaitu bahasa Galela, Tobelo, Loloda, Gorap, Laba, Tugutil, Ibu, Modole, Tobaru, Gamkonora, Wayoli, Kao, Sahu, Pagu, Ternate, Melayu Ternate, Tidore, Buli, Maba, Patani, Sawai, Makian luar, Makian Dalam, Bacan, Gane, Gebe, Taliabu, Sula, Kadai, dan Mangole. Salah satu bahasa yang hampir punah di Maluku Utara adalah bahasa Taliabu. Taliabu merupakan salah satu kabupaten dimaluku utara di Indonesia. Pulau Taliabu merupakan hasil pemekaran dari Kabupaten Kepulauan Sula.

\section{B. Kamus}

Menurut kamus besar bahasa Indonesia, pengertian dari kamus adalah buku acuan yang memuat kata dan ungkapan yang biasanya disusun menurut abjad berikut keterangan tentang maknanya, pemakaiannya, dan terjemahannya. Kamus dapat juga digunakan sebagai buku rujukan yang menerangkan makna kata-kata yang berfungsi untuk membantu seseorang mengenal perkataan baru [5].

\section{Android}

Android merupakan sistem operasi berbasis Linux untuk telepon selular, smartphone, dan komputer tablet..
Android adalah platform terbuka bagi para pengembang untuk menciptakan aplikasi mereka sendiri yang bisa dipakai bermacam-macam peranti bergerak [6].

\section{Use Case Diagram}

Use Case adalah deskripsi dari urutan aksi-aksi yang ditampilkan sistem atau aplikasi yang menghasilkan suatu hasil yang terukur bagi suatu actor [7]. Adanya use case akan lebih mempermudah seorang programmer untuk membangun sebuah sistem karena secara tidak langsung use case juga menunjukan kebutuhan dari sebuah sistem.

\section{E. Prototype}

The prototyping paradigma (Gambar 1) dimulai dengan pengumpulan persyaratan. Pembangun dan pelanggan bertemu dan mendefinisikan tujuan secara keseluruhan untuk perangkat lunak, mengidentifikasi persyaratan apapun yang diketahui, dan garis besar daerah di mana definisi lebih lanjut adalah wajib. Sebuah "desain cepat" kemudian terjadi. Desain cepat berfokus pada representasi dari aspek-aspek perangkat lunak yang akan terlihat pelanggan/pengguna (misalnya, pendekatan input dan format output). Desain cepat mengarah ke

pembangunan prototype.

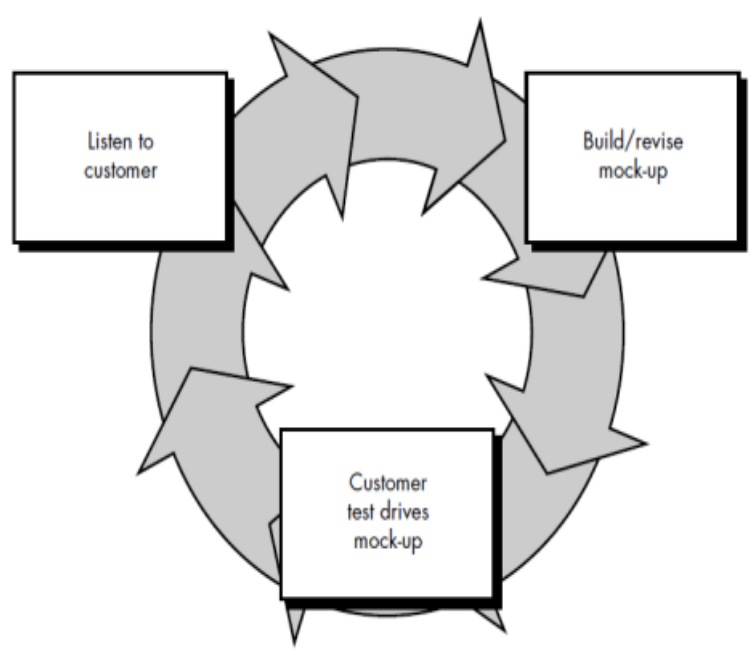

Gambar 1 Tahapan Prototype [8]

. Adapun tahapan-tahapan prototype yaitu :

\section{Listen to costumer}

Pada tahap ini dilakukan pengumpulan kebutuhan dari sistem dengan cara mendengar kebutuhan dari pelanggan. Untuk membuat suatu sistem yang sesuai kebutuhan, maka harus diketahui terlebih dahulu bagaimana sistem yang sedang berjalan untuk kemudian mengetahui masalah yang terjadi.

\section{Build/Revise Mock up}

Pada tahap ini, dilakukan perancangan dan pembuatan prototype system. Prototype yang dibuat disesuaikan dengan kebutuhan sistem yang telah 
didefinisikan sebelumnya dari kebutuhan pelanggan atau pengguna.

\section{Costumer test to driver mock-up}

Pada tahap ini, prototype dari sistem di uji coba oleh pelanggan atau pengguna. Kemudian dilakukan evaluasi kekurangan-kekurangan dari kebutuhan pelanggan. Pengembangan kemudian kembali mendengarkan keluhan dari pelanggan untuk memperbaiki prototype yang ada.

\section{F. Binary Search}

Binary Search (pencarian bagi dua) adalah metode yang digunakan untuk kebutuhan pencarian dengan waktu yang cepat. Prinsip pencarian dengan membagi data atas dua bagian. Data yang disimpan di dalam larik harus sudah terurut [9].

Binary search (pencarian biner) dapat dilakukan jika data sudah dalam keadaan urut. Dengan kata lain, apabila data belum dalam keadaan urut, pencarian biner tidak dapat dilakukan. Dalam kehidupan sehari-hari, sebenarnya kita juga sering menggunakan pencarian biner. Misalnya saat ingin mencari sesuatu kata dalam kamus [10].

\section{METODE PENELITIAN}

\section{A. Pengumpulan Data}

Pada data kamus penulis melakukan wawancara langsung dengan masyarakat Taliabu. Selain itu untuk data yang di guankan untuk penyelesaian skripsi menggunakan metode studi pustaka, wawancara, dan observasi.

\section{B. Perancangan Sistem}

Perancangan sistem diawali dengan perancangan proses aplikasi menggunakan use case diagram. Use case yang di rancang terbagi dua yaitu use case admin dan use case user. Admin di berikan hak akses berupa meng-input data kamus, lihat data kamus, dan lihat saran kata. Use case admin dapat dilihat pada gambar 2.

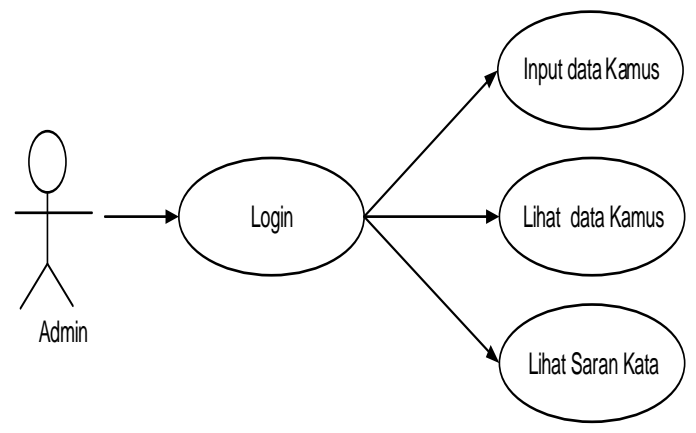

Gambar 2 Use Case Admin

User di berikan hak akses berupa mencarikata, memilih kata, melihat tentang, dan saran. Use case user dapat dilihat pada gambar 3 .

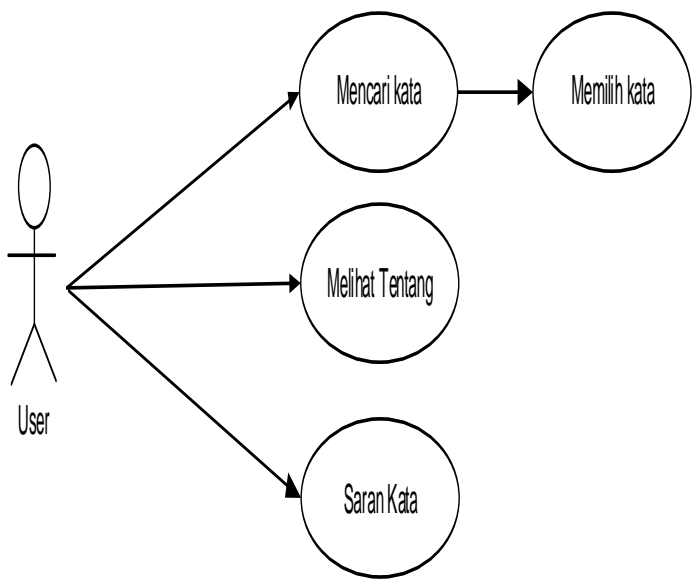

Gambar 3 Use Case User

C. Desain Database

Database yang digunakan dalam pembuatan aplikasi ini hanya berjumlah satu database dengan 4 tabel di dalamnya. Nama database yang di buat adalah kamus_taliabu dengan tabel di dalamnya adalah kata, tentang, saran dan user.

1. Tabel Kata

Tabel 1 Desain Tabel Kata

\begin{tabular}{|c|l|l|l|}
\hline No & Nama field & Type Data & Keterangan \\
\hline 1 & Id_kata & Integer & Primary key \\
\hline 2 & b_Indo & Varchar & \\
\hline 3 & bt_kd & Varchar & \\
\hline 4 & kd_Kalimat & Varchar & \\
\hline 5 & bt_mg & Varchar & \\
\hline 6 & mg_Kalimat & Varchar & \\
\hline 7 & bt_sb & Varchar & \\
\hline 8 & sb_Kalimat & Varchar & \\
\hline 9 & arti kalimat & Varchar & \\
\hline 10 & Approve & Enum & \\
\hline
\end{tabular}

2. Tabel User

Tabel 2. Desain Tabel User

\begin{tabular}{|c|l|l|l|}
\hline No & Nama field & Type Data & Keterangan \\
\hline 1 & id_user & Integer & Primary key \\
\hline 2 & Username & Varchar & \\
\hline 3 & Password & Varchar & \\
\hline
\end{tabular}

3. Tabel Saran

Tabel 3. Desain Tabel Saran

\begin{tabular}{|c|l|l|l|}
\hline No & Nama field & Type Data & Keterangan \\
\hline 1 & id_saran & Integer & Primary key \\
\hline 2 & Nama & Varchar & \\
\hline 3 & Email & Varchar & \\
\hline 4 & Isi saran & Text & \\
\hline
\end{tabular}

4. Tabel Tentang 
Tabel 4. Desain Tabel Tentang

\begin{tabular}{|c|l|l|l|}
\hline No & Nama field & Type Data & Keterangan \\
\hline 1 & Id_tentang & Integer & Primary key \\
\hline 2 & Judul & Varchar & \\
\hline 3 & Isi & Varchar & \\
\hline
\end{tabular}

\section{Algoritma atau Pseudocode}

Cara kerja algoritma binary search pada aplikasi yaitu pertama menentukan niliai awal dan nilai akhir kemudian jika nilai akhir nilai akhir lebih kecil dari nilai awal maka pencarian tidak akan jalan. Kemudian mencari nilai tengah dengan cara nilai tengah $=$ (nilai awal + nilai akhir)/2 setelah nilai tengah di dapatkan maka akan di sesauian dengan kata yang di cari apakah sudah sesuai atau belum, Jika sesuai makan akan langsung di tampilkan kata yang dicari. Jika belum sesuai maka akan di lakukan pembandingan dengan kata yang dicari apakah nilai tengah lebih kecil atau lebih besar jika lebih besar maka nilai tengah di kurangi 1 dan jika lebih kecil akan di tambahkan satu. Jika lebih besar maka nilai tengah menjadi nilai akhir kemudian kembali melakukan perhitungan mecari nilai tengah baru, namun jika nilainya lebih kecil maka nilai tengah menjadi nilai awal kemudian kembali menghitung nilai tengah yang baru hingga nilai tengah sesaui dengan kata yang dicari Adapun pseudocode algoritma Binary Search yaitu:

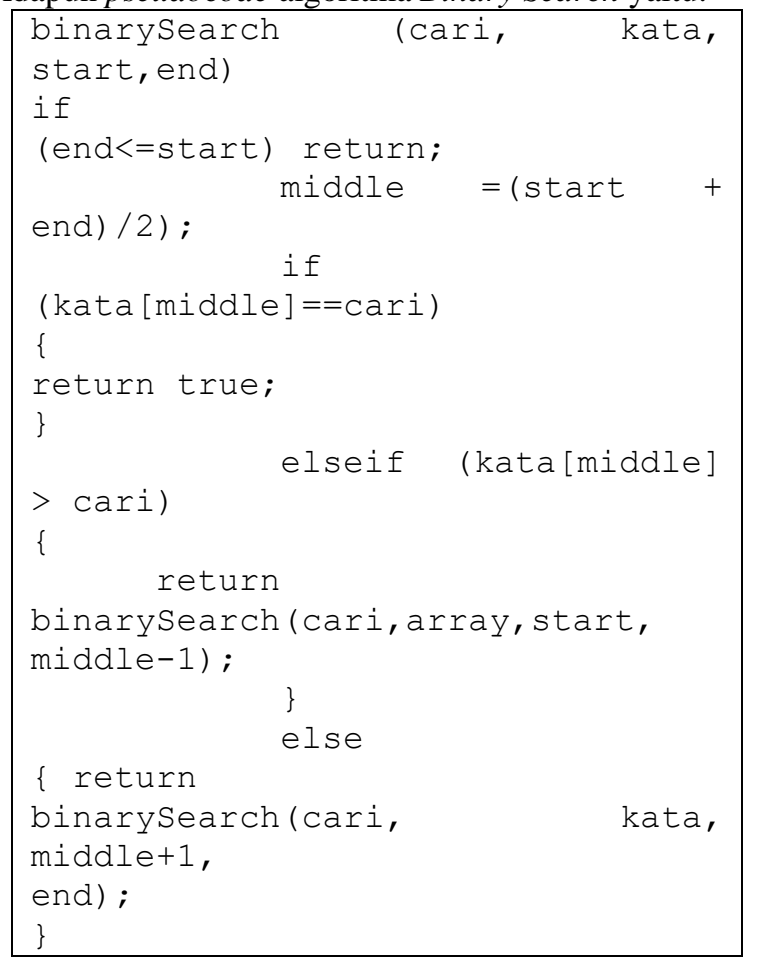

\section{HASIL DAN PEMBAHASAN}

\section{A. Implementasi Basis Data}

Pada aplikasi kamus Bahasa Taliabu dengan metode binary search berbasis android ini mengimplementasikan database dengan kamus_taliabu. Dalam database terdapat terdapat 4 tabel dengan nama tabel, tabel kata, tabel user, tabel saran, dan tabel tentang. Setiap tabel pada database kamus_taliabu tidak ada relasi, dapat dilihat pada gambar 4 .

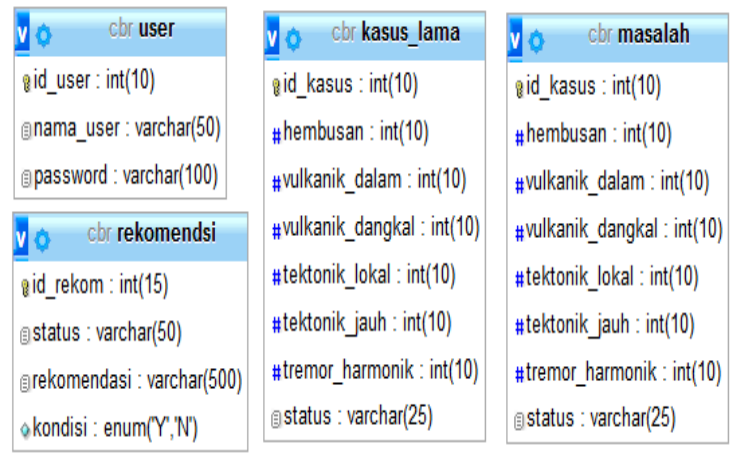

Gambar 4. Struktur Tabel Pada Basis Data

\section{B. Implementasi Interface}

Dalam aplikasi kamus Bahasa Taliabu berbasis android dengan menggunakan metode binary searach ini mengimplementasikan beberapa interface yang dimulai dari interfaces input sampai pada interfaces output. Untuk tampilan awal aplikasi dapat dilihat pada gambar 5.

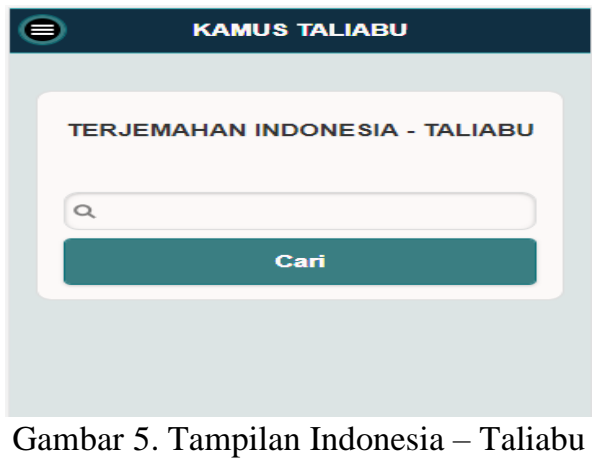

Setelah masuk ke tampilan awal selanjutnya user melakukan input-an kata yang akan di cari seperti pada gambar 6.

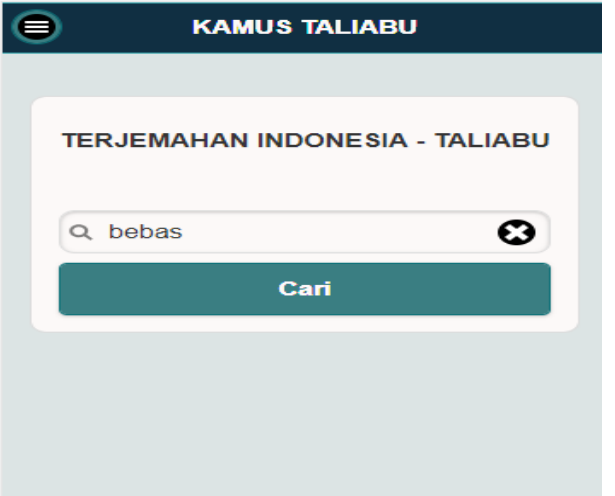

Gambar 6. Mencari Kata ‘bebas’ pada Aplikasi 
Ketika user menekan tombol cari maka aplikasi akan menampilkan kata sesuai pencarian seperti pada gambar 7.

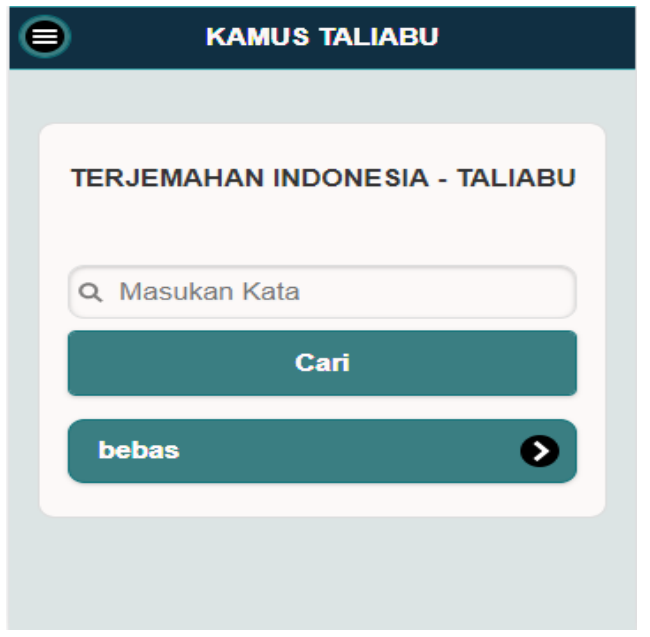

Gambar 7. Hasil Pencarian Kata Bebas

Setelah muncul kata yang dicari kemudian jika di klik maka aplikasi akan menampilkan makna kata tersebut seperti pada gambar 8 .

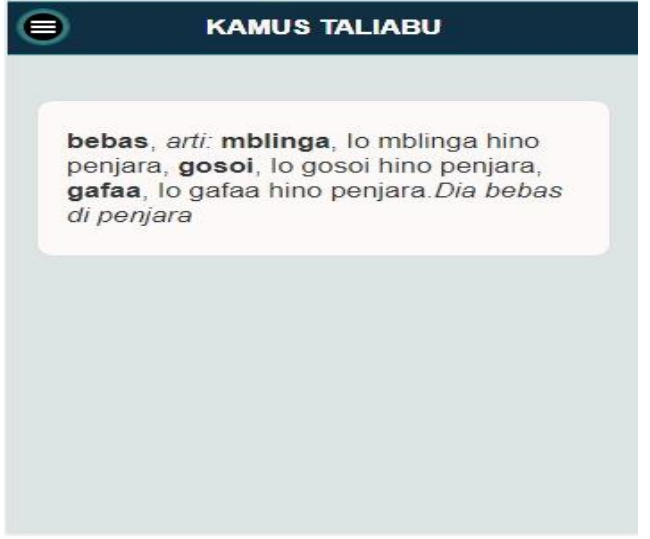

Gambar 8. Hasil terjemahan kata yang di cari

\section{Pengujian Sistem}

Bedasarkan pengujian yang telah dilakukan yaitu pengujian sistem dengan metode black box dan white box. Pada aplikasi kamus Bahasa Taliabu dengan menggunakan metode binary search yang dibuat terdiri tampilan untuk admin dan pengguna. Berdasarkan hasil pengujian blackbox di dalam tampilan admin terdapat menu lihat data kamus, Saran, dan Tentang. Sedangkan di dalam tampilan pengguna atau user terdapat menu Indonesia - Taliabu, Taliabu - Indonesia, Saran, dan Tentang. Dengan demikian maka aplikasi kamus Bahasa Taliabu dengan menggunakan metode binary search sudah berjalan sesuai dengan perancangan sistem. Sedangkan untuk pengujian whitebox terdiri dari 2 tampilan yang di uji yaitu tampilan untuk admin dan user yang dibuat dalam bentuk flowgraph yang diambil dari masing-masing flowchart dan hasil pengujian white box-nya mencari nilai Cylomatic Complexcity dan independent path yang menunjukan semua hasilnya valid.

Untuk metode binary search dapat digunakan untuk melakukan pencarian kata dengan baik karena metode ini menggunakan pencarian bagi dua dalam prosesnya. Syarat untuk metode ini berjalan dengan baik adalah database yang harus sudah terstruktur. Bagi dua yang di maksud adalah binary search akan mencari titik tengah dari data yang sudah terstruktur kemudian melakukan pencarian hingga kata di temukan. Dengan demikian penerapan algoritma binary search pada aplikasi kamus bahasa Taliabu dapat membantu menemukan dan mempercepat aplikasi dalam mecari kata untuk diterjemahkan, baik kata Indonesia-Taliabu maupun Taliabu-Indonesia.

\section{KESIMPULAN}

1. Aplikasi ini mempermudah pengguna mengetahui arti terjemahan kosakata dalam bahasa Indonesia ke bahasa Taliabu maupun sebaliknya. Aplikasi ini juga disetai dengan contoh kalimat dalam Bahasa Taliabu.

2. Pembuatan aplikasi kamus Bahasa Taliabu pada platform android dilakukan dengan bahasa pemrograman JQuery Mobile dan memanfaatkan aplikasi web 2 Apk Builder untuk mengubah aplikasi web ke mobile. Untuk pembuatan basis data menggunakan MySQL. Aplikasi kamus Taliabu ini dapat di akses jika perangkat mempunyai koneksi internet karena data pada aplikasi haris di ambil langsung dari web server.

3. Metode pengembangan perangkat lunak prototype dapat digunakan untuk pengembangan aplikasi kamus Bahasa Taliabu yang terdiri dari beberapa tahapan yaitu desain sistem dilakukan mulai dengan pembuatan UML dan diagram use case, selanjutnya pengkodean dan terakhir pengujian sistem dengan menggunakan metode blackbox dan whitebox.

4. Hasil pengujian aplikasi menggunakan metode blackbox menunjukan bahwa input, output dan interfaces pada aplikasi telah sesuai dengan perncangan sedangkan untuk penerapan metode binary search pada aplikasi kamus Bahasa Taliabu dapat menambah ketepatan dalam melakukan pencarian kata sehingga lebih mempermudah pengguna.

\section{DAFTAR PUSTAKA}

[1] I. N. Farida, "Aplikasi Kamus Indonesia-Jawa Berbasis Android," vol. 2, no. 1, pp. 1-5, 2015.

[2] A. Muhyidin, "Masa Depan Bahasa Indonesia Sebagai Bahasa Pemersatu Bangsa Dalam Bingkai Multikukulturalisme," 2009.

[3] D. E. Kurniawan and R. Simon, "Aplikasi Kamus Aneka Bahasa Daerah Berbasis Smartphone Android," 2013. 
[4] W. Kurniawati, "Menyelamatkan Bahasa Ibu Dari Kepunahan," 2008.

[5] A. N. Arrasyid, "Aplikasi Kamus Bahasa Daerah Tolaki Berbasis Android," vol. 1, no. 1, pp. 62-68, 2016.

[6] M. R. Mohamad Nur Fadzri Lamusu, Moh. Hidayat Koniyo, "Pembuatan Aplikasi Kamus 3 Bahasa Pada Smartphone Android," Karya Ilm. Mhs., 2013.

[7] M. R. G. Hattari, S. Lutfi, and A. Khairan, 2018 "Perancangan Aplikasi Android Sistem Informasi Akademik Universitas Khairun Ternate, Teknik Informatika Unkhair" JIKO, vol. 02, no. 2, pp. 7684, 2018.

[8] R. S. Pressman, software enginering. 2010.

[9] F. Rohman, P. W. Buana, A. Agung, and K. Wiranata, "Rancang Bangun Penerjemah Bahasa Indonesia ke Bahasa Jawa Berbasis Android," Merpati, vol. 3, no. 1, pp. 40-47, 2015.

[10] A. Limas, M. Z. S. Hadi, and M. Yuliana, "Aplikasi metode binary search untuk Mendeteksi penyakit tropis," pp. 1-8, 2011. 